\title{
Biochemical studies on olive leaves and oil against high sucrose diet in rabbits
}

\author{
Mohamed Lebda*, Nabil Taha, Mahdy Korshom, Abd El-Wahab Mandour and Mohamed El-Tabbakh
}

Department of Biochemistry, Faculty of Veterinary Medicine, Alexandria University, Edfina, Egypt

\begin{tabular}{l}
\hline A R T I C L E I N F O \\
\hline Keywords: \\
Olive oil, Sucrose, Lipid peroxidation, \\
Antioxidant enzymes, Testosterone
\end{tabular}

Antioxidant enzymes, Testosterone

\begin{abstract}
A B S T R A C T
Background: Olive leaves and oil's beneficial effects are not only related to its high content of oleic acid, but also to the antioxidant potential of polyphenolics. Objectives: The present study was aimed to assess the effects of olive leaves and oil treatments on high sucrose induced oxidative damage in rabbits. Methods: Forty male rabbits were allocated into four groups; control group was kept on normal basal ration, sucrose fed group was received $30 \%$ sucrose containing ration, sucrose plus olive leaves group was administered olive leaves $5 \%$ in ration beside sucrose $30 \%$ and sucrose plus olive oil group was received olive oil $5 \%$ in basal ration together with sucrose $30 \%$ for 60 days. Results: Feeding high sucrose diet significantly increased total lipid, triacylglycerol, cholesterol and LDLc levels while decreased HDL-c level with hyperglycemia. High sucrose induced hepatic damage assessed by increasing liver marker enzymes. Increased testosterone, copper levels with decreased serum zinc level were also observed. Furthermore, high sucrose diet caused an induction in oxidative stress biomarkers with subsequent depletion in antioxidant enzymes (glutathione-Stransferase and catalase) and reduced glutathione level in liver, heart and kidneys. On the other hand, treatment with olive leaves or oil improved serum lipid profile, liver functions, glucose, zinc and copper levels but decreased testosterone level. Moreover, olive leaves or oil attenuated lipid peroxidation with increase in the antioxidant enzymes. Conclusion: We concluded that olive leaves as well as oil had improved the biochemical alterations induced by feeding high sucrose diet for long time.
\end{abstract}

(c) 2013 Publisher All rights reserved.

\section{INTRODUCTION}

High-sucrose (HS) intake was shown to contribute to syndromes such as hyperlipidemia, glucose intolerance, hypertension, and atherosclerosis ${ }^{(1)}$. Numerous studies showed that a HS diet induces insulin resistance in rodents ${ }^{(2)}$. The pathogenesis of insulin resistance caused by HS is unclear. It was reported that excess circulating free fatty acids (FFA) and glucose may contribute to insulin resistance ${ }^{(3)}$.

Corresponding author: Mohamed Lebda, department of Biochemistry, Faculty of Veterinary Medicine, Alexandria University, Egypt, Tel No: +2 01008479 197, Fax. No: +2 02960 450, e-mail address: biochemistry232@yahoo.com 
On the other hand, it was reported that adipocytokines such as leptin, adiponectin, tumor necrosis factor (TNF)-a, plasminogen activator inhibitor (PAI)-, and IL-6 are secreted from adipose tissue. The alteration of lipid metabolism and the secretion of adipocytokines in adipose tissue may be critical for the development of lifestyle-related diseases such as obesity, hyperlipidemia, diabetes, hypertension, and atherosclerosis ${ }^{(4)}$.

It is known that diet rich in sucrose increases the synthesis and secretion of VLDL by the liver and induces hypertriglyceridemia in humans and rats ${ }^{(5)}$. Various in vivo studies in animals and humans had provided evidence that HSD induced hyperlipidemia and oxidative stress ${ }^{(6)}$. Moreover, McDonald ${ }^{(7)}$ reported that fructose obtained from hydrolysis of sucrose facilitate oxidative damage. High sucrose diet had been believed to affect the balance between production of free radicals and antioxidant defense mechanism and thus can cause oxidative stress. It also resulted in increment of plasma lipid peroxidation and greater susceptibility to peroxidation in various tissues ${ }^{(8)}$. El-Hafidi et al. ${ }^{(9)}$ mentioned that the activity of catalase is reduced in the sucrose fed rats liver homogenate which may be contributed to increased levels of lipid peroxidation and protein carbonylation in whole liver cells.

Olive oil is an integral ingredient in the Mediterranean diet. There is growing evidence that it may have great health benefits including the reduction in coronary heart disease risk, the prevention of some cancers and the modification of immune and inflammatory responses (10). Virgin olive oil appears to be a functional food with various components such as monounsaturated fatty acids that may have nutritional benefits. It is also a good source of phytochemicals, including polyphenolic compounds ${ }^{(11)}$. It is known that an increased consumption of monounsaturated fatty acids (MUFA) instead of polyunsaturated fatty acids (PUFA) reduced the risk of atherosclerosis because it decreased the circulating lipoprotein's sensitivity to peroxidation ${ }^{(12)}$.

Furthermore, several studies showed a direct beneficial role of olive oil in improving plasma lipids in the treatment of metabolic syndrome ${ }^{(13)}$. Unrefined or virgin olive oil had bioactive compounds with beneficial antioxidants action ${ }^{(14)}$. In addition, the phenolics extract of olive leaves decreased the concentration of TG and LDL-cholesterol and improved the level of HDL-cholesterol that had been linked to a lower risk of coronary heart disease (15)

Alirezaei et al. ${ }^{(16)}$ reported that administration of purified oleuropein from olive leaves is able to reduce the oxidative damage caused by ethanol in rat's liver and suppresses oxidative stress as monitored by the elevation of the main anti-peroxidative enzyme activities; catalase and decreases lipid peroxidation products in the rat's liver. Also, polyphenols present in olive oil such as oleuropein, hydroxytyrosol, tyrosol and caffeic acid had an important antioxidant and anti-inflammatory effect ${ }^{(17)}$.

Therefore, regular consumption of this oil in the diet provides a constant supply of potential antioxidants that could reduce oxidative stress through the inhibition of lipid peroxidation, a factor that is currently linked to a host of diseases and scavenging of free radicals ${ }^{(18)}$. The present work was designed to study the efficacy of olive oil and leaves to alleviate the biochemical alteration resulted from feeding high sucrose ration in male rabbits with special reference to antioxidant enzymes and serum testosterone level.

\section{Material and Methods}

Chemicals, reagents and medicinal plants

Cummene hydroperoxide, 1-chloro-2, 4-dinitrobenzene (CDNB), 5-5-dithiobis-2nitrobenzoic acid (DTNB) 3, 5- dichloro-2-hydroxybenzen-sulforic acid (DHBS) and 4aminophenazone (AAP) were obtained from (Sigma chemical Co. St., Louis, MO, USA). Thiobarbituric acid (TBA) and reduced glutathione (GSH) were obtained from Fluka 
Chemical Co. Trichloroacetic acid (TCA) and tris base were obtained from Merk Chemical Co. All the reagents used were of analytical grade. Kits for cholesterol, triacylglycerol, ALT, AST, ALP, GGT, total proteins, albumin were obtained from Human Company, Germany. Kits for HDL-c, LDL-c, and Zinc provided from Dialab Production and Vertrieb von chemisch Company, Austria. Kits for urea and creatinine were obtained from Vitro Scient Company, Egypt. Kits of glucose was obtained from Spin React Company, Spain. Kits of copper was obtained from Centronic GmbH Company, Germany. Kits for total lipids was obtained from FAR Srl Company, Italy. Olive leaves were gathering from some regions of Borg El-Arab (Egypt), the leaves were washed by distilled water and dried. The leaves were then powdered and passed through mesh to increase their contact with powdered ration. Virgin olive oil was purchased from Wadi Food Company, Egypt and all were identified and authenticated by botanists in the department of Botany, Faculty of Agriculture, Alexandria University, Egypt.

\section{Animals and experimental design}

Forty adult male rabbits weighing 1300-1600 g (provided from Faculty of Veterinary Medicine, Alexandria University, Egypt) were used in this study. All rabbits were kept on the basal ration composed of $18 \%$ crude protein, $14 \%$ crude fiber, not less than $2.5 \%$ fat, $0.4 \%$ calcium, $0.32 \%$ phosphorus, $1.359 \%$ magnesium and of $2600 \mathrm{Kcal}$ digestible energy/Kg ration. After acclimatization for 2 weeks, the animals were maintained in a strictly controlled temperature $\left(18 \pm 1{ }^{\circ} \mathrm{C}\right)$. Humidity was kept at $50 \%$ and the lighting cycle was $14 \mathrm{~h}$ light and $10 \mathrm{~h}$ dark with adequate ventilation. Animals were handled with human care in accordance with the National Institutes of Health guidelines. The rabbits were randomly divided into four groups each consisting of ten animals as in the following design: the first group fed on basal ration and distilled and served as control, second group received $30 \%$ sucrose containing ration. Third group received $30 \%$ sucrose containing ration and olive leaves $5 \%$ mixed with basal ration; finally forth group kept on 30\% sucrose containing ration olive oil 5\% mixed with basal ration. All treatment was continued for two month.

\section{Blood sampling and preparation}

At the end of experiment, blood samples were withdrawn from the ear vein of each rabbit and each sample was collected into clean tubes. The blood samples were allowed to coagulate and then centrifuged at $3000 \mathrm{rpm}$ for $5 \mathrm{~min}$. The separated sera were kept at $-20^{\circ} \mathrm{C}$ until used for the estimation of serum activities of ALT, AST, ALP and GGT, total protein, albumin levels and lipid profile (total lipids, total cholesterol, triacylglycerol, HDL-c, LDL-c and VLDL-c). Also, the sera were used for determination of testosterone, zinc, copper, urea, creatinine and glucose levels.

\section{Preparation of tissue sample}

The rabbits were sacrificed by slaughtering and the liver, heart and kidneys were rapidly removed. $500 \mathrm{mg}$ of each tissue was weighed and homogenized, using glass homogenizer with ice-cooled saline to prepare $25 \% \mathrm{w} / \mathrm{v}$ homogenate. The homogenate was divided into two aliquots. The first one was deproteinized with ice-cooled $12 \%$ trichloroacetic acid and the obtained supernatant, after centrifugation at $1000 \times \mathrm{g}$ was used for the estimation of reduced glutathione (GSH) content. The second aliquot was centrifuged at $1000 \times \mathrm{g}$ and the resultant supernatant was used for estimation of glutathione-S-transferase (GST) and catalase (CAT) activities, hydrogen peroxide $\left(\mathrm{H}_{2} \mathrm{O}_{2}\right)$ and malondialdehyde (MDA) levels.

\section{Biochemical analysis}

Total serum testosterone was determined according to ${ }^{(19)}$ using solid phase radioimmunoassay (RIA) kits purchased from Diagnostic Products Corporation, Los Angles, USA. Zinc level was determined according to method described by ${ }^{(20)}$. Serum Zinc forms red 
chelate complex with 2, 5-Bromo-2-pyridylzo-5-N-propyl-sulfo-propylamino-phenol. The increase of absorbance of this complex can be measured spectrophotometrically. Serum Copper level was determined according to method described by ${ }^{(21)}$. Copper forms chelate complex with 4-/93, 5-Dibromo-2-pyridylazo-N-ethyl-N-sulfopropylaniline, the increase in absorbance of this complex can be measured and is proportional to the concentration of total copper in the sample. All other serum parameters were measured spectrophotometrically using commercial kits according to the manufacturer instructions.

\section{Antioxidant status and oxidative stress indices}

The determination of tissue GSH was determined according to method described by ${ }^{(22)}$. The method based on the reduction of 5, 5 dithiobis 2- nitrobenzoic acid with glutathione to produce a yellow compound. Tissue catalase activity was determined according to method described by ${ }^{(23)}$. Catalase reacted with a known quantity of $\mathrm{H}_{2} \mathrm{O}_{2}$; the reaction is stopped after exactly one minute with catalase inhibitor. In the presence of peroxidase, remaining $\mathrm{H}_{2} \mathrm{O}_{2}$ reacted with 3, 5 Dichloro-2-hydroxybenzene sulfonic acid and 4-aminoantipyrine to form a chromophore with a color intensity inversely proportional to the amount of catalase in the original sample. Glutathione-S-transferase activity was measured spectrophotometrically at room temperature as a rate of GSH conjugation of CDNB according to ${ }^{(24)}$. Lipid peroxide as Malondialdehyde was measured spectrophotometrically after the reaction with thiobarbituric acid according to ${ }^{(25)}$. Hydrogen peroxide was determined according to method described by ${ }^{(23)}$. In the presence of peroxidase, $\mathrm{H}_{2} \mathrm{O}_{2}$ reacts with 3, 5- dichloro-2hydroxybenzen-sulforic (DHBS) acid and 4-aminophenazone (AAP) to form a chromophore.

\section{Statistical analysis}

Statistical analysis was done by one way analysis of variance (ANOVA). Means and standard error were also calculated according to SAS ${ }^{(26)}$.

\section{Results}

Effect of high sucrose diet and olive leaves or oil on lipid profile

Administration of high sucrose diet induced significant increase in the levels of serum total lipid, total cholesterol, triacylglycerol, LDL-c and VLDL-c with significant decrease in serum HDL-c level as compared to control rabbits at $\mathrm{P}<0.05 \%$ (Table 1). Treatment with olive leaves or oil significantly reduced serum levels of total lipids, total cholesterol, triacylglycerol, VLDL-c and LDL-c (non-significant decreased with olive oil) with concurrent increased serum HDL-c level when compared to high sucrose administered rabbits.

\section{Effect of high sucrose diet and olive leaves or oil on liver function}

Compared to control rabbits, feeding rabbit with high sucrose diet exhibited significant increase in the activities of serum ALT, AST, ALP and GGT and globulins with significant reduction in serum total protein and albumin levels at $\mathrm{P}<0.05 \%$ (Table 2). However, on treatment with olive leaves, there were no significant difference in the activities of serum ALT and AST, total protein, albumin and globulins value but the activities of serum ALP and GGT tend to be significantly decreased as compared to high sucrose fed rabbits. Meanwhile, administration of olive oil statistically lowered the activities of serum ALT, AST, ALP and GGT without any significant changes in the levels of serum total protein, albumin and globulins when compared to high sucrose fed group (Table 2).

Effect of high sucrose diet and olive leaves or oil on serum testosterone, zinc, copper, urea, creatinine and glucose concentrations

Administration of high sucrose diet significantly increased serum levels of testosterone, copper and glucose with significant reduction in serum zinc level without any significant changes in serum urea and creatinine levels as compared to control rabbits at $\mathrm{P}<0.05 \%$ (Table 
3). Treatment of high sucrose fed rabbit with olive leaves significantly decreased serum testosterone, copper and glucose levels with concurrent increase in the level of serum zinc level while, serum urea and creatinine values were not significantly changes when compared to high sucrose fed group. However, treatment with olive oil significantly reduced serum testosterone, copper, urea, creatinine and glucose contents with no significant change in serum zinc level as compared to high sucrose fed rabbit at $\mathrm{P}<0.05 \%$ (Table 3 ).

\section{Effect of high sucrose diet and olive leaves or oil on antioxidant status and oxidative stress indices}

As compared to control rabbits, high sucrose feeding significantly induced oxidative stress expressed in increased levels of MDA and $\mathrm{H}_{2} \mathrm{O}_{2}$ in liver, heart and kidneys at $\mathrm{P}<0.05 \%$ (Table 5) with subsequent decrease in the activities of antioxidant enzymes; GST and CAT and level of GSH in the tissues at $\mathrm{P}<0.05 \%$ (Table 4). Treatment with olive leaves or oil significantly counteract the oxidative stress as evident by the reduction in the contents of MDA and $\mathrm{H}_{2} \mathrm{O}_{2}$ in the examined tissues (Table 5) and subsequent increase in the activities if antioxidant enzymes; GST and CAT and the level of GSH in all tissues examined (Table 4) when compared to high sucrose feeding rabbits.

\section{Discussion}

\section{Effect of high sucrose diet and olive leaves or oil on lipid profile}

Feeding high sucrose caused significant elevation in serum lipid fractions with decreased level of HDL-c (Table 1). HSD causes an increase of serum TAG level and dyslipidemia as a consequence of sucrose hydrolysis into its constituents; glucose and fructose, and their conversion into TGs ${ }^{(6)}$. In this process, a few facts are important: (1) the conversion rate of fructose into lipids in the liver and the TAG secretion rate is greater than that of glucose ${ }^{(27)}$, (2) fructose administration does not stimulate the lipoprotein lipase release, and (3) the inflow of fatty acids into the liver from adipose tissue is not depressed ${ }^{(28)}$.

The obtained data was agree with Hollenbeck ${ }^{(29)}$ who reported that the increase in total lipids level after high sucrose diet may be attributed to its content of fructose which had been shown to increase plasma concentrations of triacylglycerols and cholesterol. In this respect, fructose, as a component of sucrose, is a major ingredient of many processed foods and has been proposed to contribute to the development of obesity and dyslipidemia in humans ${ }^{(30)}$. Also, short-term consumption of a high sucrose diet increased the triacylglycerol level in liver and in plasma ${ }^{(8)}$. Moreover, hypertriglyceridemia after simple carbohydrate feeding such as fructose and/or sucrose resulted from the induction of de-novo lipogenesis, the enhanced rate of hepatic VLDL-triacylglycerol synthesis and a decrease in peripheral triacylglycerol clearance ${ }^{(31)}$. In addition, Huang et al. ${ }^{(32)}$ reported that hepatic steatosis and plasma dislipidemia induced by sucrose feeding.

Treatment with olive leaves and oil resulted in significant improvement of hyperlipidemia in high sucrose fed rabbits as observed in (Table 1). Daily supplementation on top of the normal diet, of at least $4 \mathrm{~g}$ of extra virgin olive oil in mildly hypocholesterolemic subjects was associated to favorable modifications of the plasmatic lipid profile ${ }^{(33)}$. The olive oil phenolic content decreased LDL and increased HDL levels in a dose-dependent manner (34). Furthermore, Puiggros et al. ${ }^{(35)}$ reported a significant decrease in total cholesterol with the olive oil-enriched diet. Olive oil consumption increased HDL, while decreasing LDL, LDL susceptibility to oxidation and lipid peroxidation ${ }^{(36)}$. Also, Wang et al. ${ }^{(37)}$ found that the olive leave decreasing LDL-c and the anti-atherosclerotic effect of olive leaf extract was also demonstrated in rabbits fed a high lipid diet.

\section{Effect of high sucrose diet and olive leaves or oil on liver function}

The data represented in table (2) showed that high sucrose feeding caused a dramatic increase in liver enzyme markers with depletion of total protein and albumin levels. This 
came in harmony with ${ }^{(38)}$ who reported that cellular and membrane phospholipids are the major targets of damaging free radicals and therefore depletion of phospholipids in liver of high fructose-fed rats could attributed to oxidative stress and increased release of hepatic enzymes. The increased activities of ALT, AST, ALP and GGT in group fed high sucrose diet may be attributed to hepatic fatty changes and hydropic degeneration as high sucrose diet induced hepatic steatosis and increased plasma hyperlipidemia in rodents ${ }^{(39)}$.

The total protein and albumin levels were decreased as result of hyperlipidemia induced by high sucrose diet and diminished synthetic power of liver probably due to hepatocellular damage by fatty infiltration. Also, protein utilization in oxidative stress during hyperlipidemia as, protein and albumin are important component of plasma antioxidant system (thiols used to reinforce the principal antioxidant system of the body which is glutathione) when this antioxidant system is overflowed by oxidative agents ${ }^{(40)}$. These obtained data were agree with Afolayan et al. ${ }^{(41)}$ who found that total protein, albumin and albumin/globulin ratio were significantly lower in high cholesterol fed rats when compared to animals kept on basal diet.

Treatment with olive leaves or oil significantly improved liver function as showed in table (2). These obtained data agree with Alirezaei et al. ${ }^{(16)}$ who reported that the administration of oleuropein from olive oil resulted in reduction of transaminases activity in serum of the oleuropein group compared to ethanol-treated rats. Also, Nakbi et al. ${ }^{\left({ }^{42)}\right.}$ found that the extra virgin olive oil improved the elevated hepatic enzymes induced by 2, 4Dichlorophenoxyacetic acid in rats. Furthermore, Hernández et al. ${ }^{(43)}$ reported that treatment with a balanced diet rich in olive oil contributed to the recovery of the liver from hepatic steatosis. This was achieved by decreasing activation of hepatic satellite cells by MUFAs, which are less susceptible to lipid peroxidation compared to PUFAs.

Moreover, previous studies carried out in fibrotic rats showed that olive oil, in contrast to polyunsaturated oils, could protect against the development of fibrosis ${ }^{(44)}$. Our obtained results also revealed that, treatment with olive oil or leaves don't ameliorated the decreasing effect of (total protein, albumin and $\mathrm{A} / \mathrm{G}$ ) resulted from high sucrose diet in treated animals. This result agree with Rupić et al. ${ }^{(45)}$ who mentioned that no significant differences in the concentration of total proteins, albumin, alpha1, alpha2, beta and gamma globulin in the serum of rabbits in control group and in those received dried olive cake.

Effect of high sucrose diet and olive leaves or oil on testosterone, zinc, copper, urea, creatinine and glucose levels

Regarding testosterone concentration, high sucrose diet significantly increased serum testosterone level which may be attributed to increased caloric consumption which had been shown to elevate testosterone level, while decrease caloric intake depress it ${ }^{(46)}$. The obtained data belonging to the effect of olive oil on testosterone concentration nearly agree with those obtained by Najafizadeh et al. ${ }^{(47)}$ who found that the hydro-alcoholic olive (Oleaeuropaea) extract significantly decreased serum testosterone as well as sperm count, sperm motility, the weight of prostate, testis, epididymis, seminal vesicle. Also, Weber et al. ${ }^{(48)}$ reported that the olive is phytoestrogen which may has an inhibitory effect on the enzyme 17B- hydroxy steroid hydrogenase therefore; the synthesis of testosterone in adrenal cortex is reduced. Another explanation for decreasing testosterone level may be attributed to hypocholesterolemic effect of olive leaves and oil according to Alirezaei et al. ${ }^{(16)}$ which may decrease the testicular testosterone synthesis.

Concerning zinc level, our study revealed that high sucrose diet significantly decreased serum zinc level which may be attributed to hyperlipidemia and oxidative stress and subsequently utilization of zinc as antioxidant. This result was in harmony with Ramalingam and Subrahmanyam ${ }^{(49)}$ who found that serum zinc level significantly reduced in high fat fed 
rabbits than the control group. Increased zinc level after treatment with olive leaves may be attributed to potent antioxidant effect of olive leaves constituents (oleuropein) which prevent zinc depletion in oxidative process occurred in hyperlipidemic state and this was supported by Al-Azzawie and Alhamdani ${ }^{(50)}$ who reported that the positive impact of treatment with crude oleuropein on the antioxidant enzymes GPx, GR, CAT and SOD observed could be explained with two possible mechanisms. First, the antioxidative effect of oleuropein may prevent further glycosylation and peroxidation of proteins by interacting with free radicals and hence minimizing their noxious effects. Second, oleuropein may induce protein synthesis of these enzymes that explains the observed elevated activity after treatment.

Regarding the effect of high sucrose diet on serum copper level, our results were in agreement with Adekunle et al. ${ }^{(51)}$ who reported that an increase in serum and tissue concentrations of lipids was accompanied with elevated serum copper concentration. Moreover, the increased concentration of lipid peroxides (malondialdehyde) which is an index of oxidative stress was found in rats given atherogenic diet. There is evidence that copper and zinc have pro-oxidant and antioxidant properties respectively, so that their imbalance may be expected in the oxidative stress associated conditions ${ }^{(52)}$. The significant decrease in serum copper level in groups kept on olive leaves or oil may be attributed to olive leaves and oil had hypolipidemic and antioxidant effect.

Our results regarding blood glucose level, high sucrose diet increased serum glucose level. In animal model of experimental diabetic diet containing higher level of fructose had been reported to contribute to a metabolic disturbance in animal models and result in hyperglycemia and hyperlipidemia ${ }^{(53)}$. There are many studies demonstrated the association between high fructose diet with elevation of plasma glucose, insulin and triglycerides in animal models. A $10 \%(\mathrm{w} / \mathrm{v})$ fructose solution given for 12 weeks period increased blood glucose and TG level in Wistar rats ${ }^{(54)}$. In another report, a $10 \%(\mathrm{w} / \mathrm{v})$ of HFD supplementation for four weeks had been shown to induce insulin resistance in male Spraguedawley rats ${ }^{(55)}$.

Furthermore, Yadav et al. ${ }^{(56)}$ showed that a $21 \%(\mathrm{w} / \mathrm{v})$ concentration of fructose in diet conferred a significant increase in blood glucose and TG after eight weeks on the diet regimen. In another study, a high fructose diet $(10 \% \mathrm{w} / \mathrm{v})$ for eight weeks had been shown to induce diabetes mellitus type 2 in two-month old male Sprague-dawley rats ${ }^{(57)}$.

Treatment with olive leaves or oil significantly reduced serum glucose level. Jamal and Ibrahim ${ }^{(58)}$ found that four weeks of consumption of olive oil significantly lowered the levels of fasting blood glucose, triglycerides, total cholesterol, and low density lipoproteins in diabetic patients. Also, Eidi et al. ${ }^{(59)}$ mentioned that in streptozotocin (STZ)-induced diabetic rats, olive leaf extract decreased serum concentration of glucose implying that olive leaf extract is more effective than glibenclamide and may be of use as an antidiabetic agent.

\section{Effect of high sucrose diet and olive leaves or oil on oxidative stress markers and antioxidant status}

The data represented in table $(4,5)$ showed that high sucrose diet significantly increased MDA and $\mathrm{H}_{2} \mathrm{O}_{2}$ with concurrent decrease in the antioxidant status in liver, heart and kidneys. These results came in harmony with Nandhini et al. ${ }^{(60)}$ who mentioned that male Wistar rats received fructose enriched diet resulted in increased lipid peroxidation and impaired antioxidant status. Fructose feeding can induce free radical formation by a number of mechanisms. It causes down regulation of the key enzymes of the hexose monophosphate pathway, namely glucose-6-phosphate dehydrogenase and 6-phosphogluconate dehydrogenase that generate a reduced environment in the form of NADPH and NADH, impaired regeneration of NADPH could result in an increased oxidative state of the cell ${ }^{(61)}$. Moreover, Srividhya and Anuradha ${ }^{(62)}$ reported that increases in the levels of the 
thiobarbituric acid-reactive substances (TBARS) and hydroperoxides were observed in the liver of fructose-fed rats.

Treatment with olive leaves or oil significantly decreased lipid peroxidation with enhancement of antioxidants. These results came with Masella et al. ${ }^{(63)}$ who found that oleuropein increased the expression of glutathione related enzymes at the transcriptional level. Also, olive leaves extract was shown to have a modulatory effect on the expression of the enzyme SOD in response to oxidative stress in vitro ${ }^{(64)}$. Treatment with crude oleuropein to diabetic rabbits showed a significant restoration in the levels of glutathione, $\beta$ carotene and vitamin $\mathrm{E}$ and $\mathrm{C}$. Moreover, multiple mechanisms had been proposed to explain beneficial effects of Mediterranean olive oil diet. These mechanisms include: decrease in LDL cholesterol, increase HDL-cholesterol, and reduction of oxidative stress due to polyphenols and flavonoids, which may act as scavengers and protect heart tissue and LDL from free radical damage ${ }^{(65)}$.

Virgin olive oil provides a rich variety of natural antioxidants including carotenoids, tocopherols, and polyphenols. These minor compounds may act by different mechanisms to confer an effective defense system against free radical attack. They seem to have a high antioxidant activity and provide greater stability to olive oil. Antioxidant capacity of olive oil can be attributed to the increase in tissue sensitivity to the lipid antioxidant effect of vitamin $\mathrm{E}^{(66)}$. Another possibility comes from some evidence that $\beta$-sitosterol and the polyphenols in olive oil (oleuropein, tyrosol, hydroxytyrosol, and caffeic acid) inhibit the formation of oxygen reactive species ${ }^{(67)}$, reduce the susceptibility of low density lipoprotein oxidation, erythrocyte membranes to lipid peroxidation ${ }^{(68)}$. Moreover, Kasdallah-Grissa et al. (69) showed that the oral supplementation of olive oil to rats administered ethanol chronically restored damage caused to the liver by inhibiting lipid peroxidation and improving enzymatic activities. The mechanism proposed to explain the positive effects of olive oil may be attributed to its richness in MUFA, mainly oleic acid which has different effects on lipid profiles and peroxidation in rabbit hepatic mitochondria ${ }^{(70)}$.

\section{Conclusion}

Our results concluded that, high sucrose diet increase the serum lipid profile and glucose level. Also, HSD increased hepatic injuries and the levels of testosterone and zinc. Furthermore, the oxidative processes will be increased with depletion of the antioxidant enzymes in tissues of heart, kidney and liver. On the other hand olive leaves and oil improved the lipid profile, liver function, oxidative processes and increased antioxidant enzymes.

\section{References}

(1) Fried, SK and SP, Rao., 2003. Sugar, hypertriglyceridemia, and cardiovascular disease. Am J Clin Nutr, 78: 873S-880S.

(2) Ryu, M and Y, Cha., 2003. The Effects of a High-fat or High-sucrose Diet on Serum Lipid Profiles, Hepatic Acyl-CoA Synthetase, Carnitine Palmitoyl transferase-I, and the Acetyl-CoA Carboxylase mRNA Levels in Rats. Journal of Biochemistry and Molecular Biology, 36 (3):312-318.

(3) Tomas, E., YS, Lin., Z, Dagher., A, Saha., Z, Luo., Y, Ido and NB, Ruderman., 2002. Hyperglycemia and insulin resistance: possible mechanisms. Ann New York Acad Sci, 967:43-51.

(4) Sumiyoshi, M., M, Sakanaka and Y, Kimura., 2006. Chronic Intake of High-Fat and High-Sucrose Diets Differentially Affects Glucose Intolerance in Mice. J Nutr, 136: 582587.

(5) Saku, K., T, Okamoto., Y, Takeda., S, Jimi., B, Zhang., H, Bai., R, Liu and K, Arakawa., 1996. Short-term effects of a high-sucrose diet on plasma lipid, lipoprotein cholesterol, tissue lipoprotein lipase and hepatic triacylglyceride lipase in rats. Artery, 22: 36-48. 
(6) Diniz, Y.S., KKHR, Rocha., GA, Souza., CM, Galhardi., GMX, Ebaid., HG, Rodrigues., JLVB, Novelli-Filho., AC, Cicogna and ELB, Novelli., 2006. Effects of N-acetylcysteine on sucrose-rich diet-induced hyperglycaemia, dyslipidemia and oxidative stress in rats. Eur $J$ Pharmacol, 543: 151-157.

(7) McDonald, RB. 1995. Influence of dietary sucrose on biological aging. American Journal of Clinical Nutrition, 62:2845-93S.

(8) Busserolles, J., E, Rock., E, Gueux., A, Mazur., P, Grolier and Y, Rayssiguier., 2002. Short-term consumption of a high-sucrose diet has a prooxidant effect in rats. $\mathrm{Br} J \mathrm{Nutr}$, 8:337-342.

(9) El-Hafidi, M., A, Ruiz-Ramírez., M, Chávez-Salgado., JA, Peñeda-Flores., E, Zapata and F, Masso., 2011. High-sucrose diet increases ROS generation, FFA accumulation, UCP2 level, and proton leak in liver mitochondria. Am J Physiol Endocrinol Metab, 301: E1198E1207.

(10) Visioli, F and C, Galli., 2002. Biological properties of olive oil phytochemicals. Crit Rev Food Sci Nutr, 42(3):209-221.

(11) Lavelli, V. 2002. Comparison of the antioxidant activities of extra virgin olive oils. $J$ Agric Food Chem, 50 (26):7704-7708.

(12) Moreno, JJ and MT, Mitjavilab., 2003. The degree of unsaturation of dietary fatty acids and the development of atherosclerosis (Review). J Nutr Biochem, 14 (4):182-195.

(13) Alonso, A., V, Ruiz-Gutierrez and M.A. Martínez-González, 2006. Monounsaturated fatty acids, olive oil and blood pressure: epidemiological, clinical and experimental evidence. Public Health Nutr, 9: 251-257.

(14) Kris-Etherton, PM., KD, Hecker., A, Bonanome., SM, Coval., AE, Binkoski., KF, Hilpert., AE, Griel and TD, Etherton., 2002. Bioactive compounds in foods: their role in the prevention of cardiovascular disease and cancer. Am J Med, 113 9B: 71S-88S.

(15) Jemai, H., M, Bouaziz., I, Fki., A, El Feki and S, Sayadi., 2008. Hypolipidimic and antioxidant activities of oleuropein and its hydrolysis derivative-rich extracts from Chemlali olive leave. Chem Biol Interact, 176:88-98.

(16) Alirezaei, M., G, Jelodar., P, Niknam., Z, Ghayemi and S, Nazifi., 2011. Betaine prevents ethanol-induced oxidative stress and reduces total homocysteine in the rat cerebellum. J Physiol Biochem, 67: 605-612.

(17) Covas, M.I., K, Nyyss"onen., H.E, Poulsen., J, Kaikkonen., H.J.F, Zunft and H, Kiesewetter., 2006. The effect of polyphenols in olive oil on heart disease risk factors. Ann Int Med, 145: 333-341.

(18) Leger, CL., N, Kadri-Hassani and B, Descomps., 2000. Decreased superoxide anion production in cultured human promonocyte cells (THP-1) due to polyphenol mixtures from olive oil processing wastewaters. J Agric Food Chem, 48:5061-5067.

(19) Demetriou, JA. 1987. Testosterone in methods. In Clinical Chemistry TECH, A.G. and Kaplan, L.A., (Eds) $2^{\text {nd }}$ Ed. CV Mosby CO., pp.268.

(20) Johnsen, A and R, Eliasson., 1987. Evaluation of a commercially available kit for the colorimetric determination of zinc. International Journal of Andrology, 10 (2): 435- 440.

(21) Abe, A., S, Yamashita and A, Noma., 1989. Clin Chem, 35: 552- 554.

(22) Beutler, E., O, Duron and B.M. Kellin., 1963. Improved method for the determination of blood glutathione. J Lab Clin Med, 61:882- 888.

(23) Aebi, H. 1984. Catalase in vitro. Methods in enzymology, 105:121-6.

(24) Habig, WH., MJ, Pabst and WB, Jakoby., 1974. Glutathione S-transferases: the first enzymatic step in mercapturic acid formation. J Biol Chem, 249: 7130-7139.

(25) Satoh, K. 1978. Serum lipid peroxide in cerebrovascular disorders determined by a new colorimetric method .Clin Chem Acta, 90: 37 - 42. 
(26) SAS, 2002. Statistical Ananlysis System, Version 9, Users Guide, SAS institute, INC., Cary, NC,USA.

(27) Bar-On, H and Y, Stein., 1994. Effect of glucose and fructose administration on lipid metabolism in the rat. $J$ Nutrition, 94: 95-105.

(28) Kannan, R., N, Baker and KR, Bruckdorfer., 1981. Secretion and turnover of very low density lipoprotein triacylglycerols in rats fed chronically diets rich in glucose and fructose. $J$ Nutr, 111: 1216-1223.

(29) Hollenbeck, CB. 1993. Dietary fructose effects on lipoprotein metabolism and risk for coronary artery disease. Am J Clin Nutr, 58: 800s-809s.

(30) Gross, LS., L, Li., ES, Ford and S, Liu., 2004. Increased consumption of refined carbohydrates and the epidemic of type 2 diabetes in the United States: an ecologic assessment. Am J Clin Nutr, 79: 774-779.

(31) Suzuki, T and H, Hara., 2004. Ingestion of guar gum hydrolysate, a soluble and fermentable non digestible saccharide, improves glucose intolerance and prevents hypertriglyceridemia in rats fed fructose. $J$ Nutr, 134:1942-1947.

(32) Huang, W., N, Dedousis and RM, O'Doherty., 2007. Hepatic steatosis and plasma dyslipidemia induced by a high-sucrose diet are corrected by an acute leptin infusion. $J$ Appl Physiol, 102: 2260-2265.

(33) Violante, B., L, Gerbaudo., G, Borretta and F, Tassone., 2009. Effects of Extra Virgin Olive Oil Supplementation at Two Low Different Doses on Lipid Profile in Mild Hypercholesterolemic Subject: A Randomized Clinical Trial. J Endocrinol Invest, 32:794796.

(34) Weinbrenner, T., M, Fito., R, de la Torre., GT, Saez., P, Rijken., C, Tormos., S, Coolen., MF, Albaladejo., S, Abanades., H, Schroder., J, Marrugat and MI, Covas., 2004. Olive oils high in phenolic compounds modulate oxidative/antioxidative status in men. $J$ Nutr, 134(9):2314-2321.

(35) Puiggrós, C., P, Chacón., LI, Armadans., J, Clapés and M, Planas., 2002. Effects of oleic-rich and omega-3-rich diets on serum lipid pattern and lipid oxidation in mildly hypercholesterolemic patients. Clin Nutr, 21:79-87.

(36) Cullinen, K. 2006. Olive Oil in the Treatment of Hypercholesterolemia. Med Health Res, 89:113-117.

(37) Wang, L., C, Geng., L, Jiang., G, Gong., D, Liu., E, Yoshimurah and L, Zhong., 2008. The anti-atherosclerotic effect of olive leaf extract is related to suppressed inflammatory response in rabbits with experimental atherosclerosis. Eur J Nutr, 47: 235-243.

(38) Slatter, DA., CH, Bolton and N, Bailey., 2000. The importance of lipid derived malondialdehyde in diabetes mellitus. Diabetelogia, 43: 550-557.

(39) Anuradha, C.V. and P, Anurag., 2002. Metformin improves lipid metabolism and attenuates lipid peroxidation in high fructose-fed rats. Diabetes Obes Metab, 4: 36-42.

(40) Ngondi, JL., CFB, Nyangono., RMC, Naganoum., D, Kuate and JE, Oben., 2012. Effect of Guibourtia tessmannii extracts on blood lipids and oxidative stress markers in triton WR1339 and high fat diet induced hyperlipidemic rats. Biol and Med Res, 4 (1): 1-9.

(41) Afolayan, A.J., O.S Olorueannisola and G, Bradley., 2012. Protective effect of T. violacea Rhizome extract against hypercholesterolemia induced oxidative stress in Wistar rats. Molecules, 17: 6033- 6045.

(42) Nakbi, A., W, Tayeb., A, Grissa., M, Issaoui., S, Dabbou., I, Chargui., M, Ellouz., A, Miled and M, Hammami., 2010. Effects of olive oil and its fractions on oxidative stress and the liver's fatty acid composition in 2,4-Dichlorophenoxyacetic acid-treated rats. Nutrition and Metabolism, 7:80-87.

(43) Hernández, R., E, Martínez-Lara., A, Cañuelo., ML, Del Moral., S, Blanco., E, Siles., A, Jiménez., JA, Pedrosa and MA, Peinado., 2005. Steatosis recovery after treatment with a 
balanced sunflower or olive oil-based diet: involvement of perisinusoidal stellate cells. World J Gastroenterol, 11: 7480-7485.

(44) Szende, B., F, Timár and B, Hargitai., 1994. Olive oil decreases liver damage in rats caused by carbon tetrachloride (CCl4). Exp Toxicol Pathol, 46: 355-359.

(45) Rupić, V., J, Škrlin., S, Mužic., V, Šerman., N, Stipič and L, Bačar-Huskić., 1999. Proteins and fats in the serum of rabbits fed different quantities of dried olive cake. Acta Vet Brno, 68: 91-98.

(46) Volek, J.S. 1997. Energy metabolism and high intensity exercise: Dietary concerns for optimal recovery. Sten Cond, 19(5): 26-37.

(47) Najafizadeh, P., F, Dehghani., SM, Panjeh and TS, Hamzei., 2013. The effect of a hydro-alcoholic extract of olive fruit on reproductive argons in male Sprague-dawley rat. Iran J Reprod Med, 11 (4): 293-300.

(48) Weber, K., K, Setchell., D, Stocco and E, Lephart., 2001. Dietary soy-phytoestrogens decrease testosterone levels and prostate weight without altering LH, prostate 5alphareductase or testicular steroidogenic acute regulatory peptide levels in adult male SpragueDawley rats. J Endocrinol, 170: 591-599.

(49) Ramalingam, K and G, Subrahmanyam., 2012. Serum zinc status, oxidative stress \& chronic low grade inflammation in high fat diet fed rabbits. International Journal of Analytical, Pharmaceutical and Biomedical Sciences, 1 (2): 1233-1238.

(50) Al-Azzawie, HF M.S. and Alhamdani., 2006. Hypoglycemic and antioxidant effect of oleuropein in alloxan-diabetic rabbits. Life Sci, 78:1371-1377.

(51) Adekunle, A.S., A.L. Adedeji., E.O. Oyewo., O.T. Adedosu and A.T. Omotoso., 2013. Hyperlipidemia induced by atherogenic diet enhanced oxidative stress in the kidney and inflammatory responses: an in-vivo study. Asian Journal of Natural and Applied Sciences, 2 (1): 91-112.

(52) Guo, CH and CL, Wang., 2013. Effects of Zinc Supplementation on Plasma Copper/Zinc Ratios, Oxidative Stress, and Immunological Status in Hemodialysis Patient. Int J Med Sci, 10 (1): 79-89.

(53) Kasim-Karakas, S., H, Vriend., R, Almario., L, Chow and M, Goodman., 1996. Effects of dietary carbohydrates on glucose and lipid metabolism in golden Syrian hamsters. J Lab. Clin Med, 128: 208-213.

(54) Dai, S and J, McNeill., 1995. Fructose-induced hypertension in rats is concentration-and duration dependent 1. J Pharmacol Toxicol Methods, 33: 101-107.

(55) Carranza, A., C, Mendez., M, Barontini and S, Nowicki., 2004. Insulin enhances 1-dopa renal proximal tubule uptake: A regulatory mechanism impaired in insulin resistance. Eur $J$ Physiol, 448: 85-92.

(56) Yadav, H., S, Jain and P, Sinha., 2007. Antidiabetic effect of probiotic dahi containing Lactobacillus acidophilus and Lactobacillus casei in high fructose fed rats. Nutrition, 23: 6268.

(57) Berkane, A., F, Tranchida., S, Pietri., M, Culcasi., H, Nguyen and D, Merlin., 2008. High energy fructose diet induced type 2 diabetes in rats. Atherosclerosis Suppl, 9: 71.

(58) Jamal, AA and A, Ibrahim., 2011. Effects of olive oil on lipid profiles and blood glucose in type 2 diabetic patients. Int J Diabetes and Metab, 19:19-22.

(59) Eidi, A., M, Eidi and R, Darzi., 2009. Antidiabetic effect of Olea europaea L. in normal and diabetic rats. Phytother Res, 23:347-350.

(60) Nandhini, AT., VA, Thirunavukkarasu., MK, Ravichandran and CV, Anuradha., 2005. Effect of taurine on biomarkers of oxidative stress in tissues of fructose-fed insulin-resistant rats. Singapore Med J, 46 (2): 82-91. 
(61) Fields, M., CG, Lavis., M, Lore and WS, Antholine., 1992. The influence of gender on developing copper deficiency and on free radical generation of rats fed a fructose diet. Metabolism, 41:989-994.

(62) Srividhya, S and CV, Anuradha., 2002. Metformin improves liver antioxidant potential in rats fed a high-fructose diet. Asia Pacific J Clin Nutr, 11(4): 319-322.

(63) Masella, R., R, Vari., M, D`1Archivio., R, Di Benedetto., P, Matarrese and W, Malorni., 2004. Extra virgin olive oil biophenols inhibit cell-mediated oxidation of LDL by increasing the mRNA transcription of glutathione-related enzymes. J Nutr, 134:785-791.

(64) Madar, Z., N, Maayan., O, Sarit and A, Eliraz., 2004. Antioxidants modulate the nitric oxide system and SOD activity and expression in rat epithelial lung cells. Asia Pacific Journal of Clinical Nutrition, 13: S101-108S.

(65) Pérez-Jiménez, F., J, Ruano., P, Perez-Martinez., F, Lopez-Segura and J, LopezMiranda., 2007. The influence of olive oil on human health: not a question of fat alone. Mol Nutr Food Res, 51:1199-1208.

(66) Quiles, JL., MC, Ramírez-Tortosa., S, Ibáñez., J, Alfonso González., GG, Duthie and JR, Huertas., 1999. Vitamin E supplementation increases the stability and the in vivo antioxidant capacity of refined olive oil. Free Radic Res, 31:S129-135.

(67) Moreno, J., T, Carbonell., T, Sánchez., S, Miret and MT, Mitjavila., 2001. Olive oil decreases both oxidative stress and the production of arachidonic acid metabolites by the prostaglandin G/H synthase pathway in rats macrophages. J Nutr, 131:2145-9.

(68) Manna, C., F, Della Ragione., V, Cucciolla., A, Borriello., S, D'Angelo and P, Galletti., 1999. Biological effects of hydroxytyrosol, a polyphenol from olive oil endowed with antioxidant activity. Adv Exp Med Biol, 472:115-130.

(69) Kasdallah-Grissaa, A., A, Nakbi., N, Koubaa., S, El-Fazaâ., N, Gharbi., A, Kamoun and M, Hammami., 2008. Dietary virgin olive oil protects against lipid peroxidation and improves antioxidant status in the liver of rats chronically exposed to ethanol. Nutrition Research, 28 472-479.

(70) Ochoa-Herrera, JJ., JR, Huertas., JL, Quiles and J, Mataix., 2001. Dietary oils high in oleic acid, but with different non-glyceride contents, have different effects on lipid profiles and peroxidation in rabbit hepatic mitochondria. J Nutr Biochem, 12(6):357-364. 
Table 1: Mean \pm SE of total lipids, triacylglycerol, total cholesterol, HDL-c, LDL-c and VLD-c $(\mathrm{mg} / \mathrm{dl})$ levels in rabbit's serum kept on high sucrose diet, olive leaves and oil

\begin{tabular}{lcccc}
\hline Control group & $\begin{array}{c}\text { High sucrose } \\
\text { group }\end{array}$ & $\begin{array}{c}\text { High sucrose }+ \\
\text { Olive leaves } \\
\text { group }\end{array}$ & $\begin{array}{c}\text { High sucrose }+ \\
\text { Olive oil group }\end{array}$ \\
\hline T.lipids & $255.60 \pm 4.98^{\mathbf{c}}$ & $407.60 \pm 7.50^{\mathbf{a}}$ & $306.20 \pm 13.46^{\mathbf{b}}$ & $334.60 \pm 18.78^{\mathbf{b}}$ \\
TAG & $53.50 \pm 2.01^{\mathbf{d}}$ & $242.86 \pm 15.43^{\mathbf{a}}$ & $135.00 \pm 5.00^{\mathbf{c}}$ & $171.38 \pm 4.38^{\mathbf{b}}$ \\
TCH & $60.00 \pm 4.30^{\mathbf{b}}$ & $72.14 \pm 3.60^{\mathbf{a}}$ & $55.00 \pm 3.02^{\mathbf{b}}$ & $60.57 \pm 3.15^{\mathbf{b}}$ \\
HDL-c & $24.80 \pm 1.62^{\mathbf{b}}$ & $15.00 \pm 1.00^{\mathbf{c}}$ & $23.40 \pm 1.66^{\mathbf{b}}$ & $30.40 \pm 1.54^{\mathbf{a}}$ \\
LDL-c & $15.80 \pm 2.82^{\mathbf{b}}$ & $23.80 \pm 2.42^{\mathbf{a}}$ & $16.00 \pm 1.30^{\mathbf{b}}$ & $20.25 \pm 1.11^{\mathbf{a}}$ \\
VLDL-c & $10.70 \pm 0.40^{\mathbf{d}}$ & $48.57 \pm 3.09^{\mathbf{a}}$ & $24.08 \pm 0.87^{\mathbf{c}}$ & $34.28 \pm 0.88^{\mathbf{b}}$ \\
\hline
\end{tabular}

The means within the same row with different superscript letters are significantly differed at $(\mathrm{P}<0.05)$

Table 2: Mean \pm SE of ALT, AST, ALP and GGT (U/l) activities and total protein, albumin and globulins (g/dl) levels in rabbit's serum kept on high sucrose diet, olive leaves and oil

\begin{tabular}{lcccc}
\hline & Control group & $\begin{array}{c}\text { High sucrose } \\
\text { group }\end{array}$ & $\begin{array}{c}\text { High sucrose }+ \\
\text { Olive leaves } \\
\text { group }\end{array}$ & $\begin{array}{c}\text { High sucrose }+ \\
\text { Olive oil group }\end{array}$ \\
\hline ALT & $38.30 \pm 0.94^{\mathbf{b}}$ & $48.75 \pm 2.47^{\mathbf{a}}$ & $46.33 \pm 0.61^{\mathbf{a}}$ & $25.38 \pm 2.57^{\mathbf{c}}$ \\
AST & $30.06 \pm 0.41^{\mathbf{b}}$ & $36.25 \pm 3.30^{\mathbf{a}}$ & $35.00 \pm 3.03^{\mathbf{a}}$ & $26.50 \pm 1.44^{\mathbf{c}}$ \\
ALP & $629.50 \pm 89.88^{\mathbf{b}}$ & $883.00 \pm 10.66^{\mathbf{a}}$ & $502.50 \pm 81.69^{\mathbf{b}}$ & $654.25 \pm 12.53^{\mathbf{b}}$ \\
GGT & $4.15 \pm 0.30^{\mathbf{c}}$ & $25.23 \pm 1.60^{\mathbf{a}}$ & $11.10 \pm 1.38^{\mathbf{b}}$ & $8.14 \pm 1.53^{\mathbf{b c}}$ \\
T.protein & $4.95 \pm 0.06^{\mathbf{a}}$ & $4.55 \pm 0.13^{\mathbf{b}}$ & $4.40 \pm 0.15^{\mathbf{b}}$ & $4.53 \pm 0.15^{\mathbf{b}}$ \\
Albumin & $3.97 \pm 0.09^{\mathbf{a}}$ & $3.03 \pm 0.09^{\mathbf{b}}$ & $2.90 \pm 0.11^{\mathbf{b}}$ & $3.13 \pm 0.06^{\mathbf{b}}$ \\
Globulins & $1.00 \pm 0.06^{\mathbf{b}}$ & $1.43 \pm 0.09^{\mathbf{a}}$ & $1.50 \pm 0.14^{\mathbf{a}}$ & $1.41 \pm 0.14^{\mathbf{a}}$ \\
\hline
\end{tabular}

The means within the same row with different superscript letters are significantly differed at $(\mathrm{P}<0.05)$

Table 3: Mean $\pm \mathrm{SE}$ of testosterone $(\mathrm{ng} / \mathrm{ml})$, zinc and copper (ug/dl), urea, creatinine and glucose (mg/dl) levels in rabbit's serum kept on high sucrose diet, olive leaves and oil

\begin{tabular}{lcccc}
\hline & Control group & $\begin{array}{c}\text { High sucrose } \\
\text { group }\end{array}$ & $\begin{array}{c}\text { High sucrose }+ \\
\text { Olive leaves } \\
\text { group }\end{array}$ & $\begin{array}{c}\text { High sucrose + } \\
\text { Olive oil group }\end{array}$ \\
\hline Testosterone & $1.86 \pm 0.19^{\mathbf{b}}$ & $2.20 \pm 0.28^{\mathbf{a}}$ & $0.41 \pm 0.07^{\mathbf{c}}$ & $0.35 \pm 0.06^{\mathbf{c}}$ \\
Zinc & $294.75 \pm 6.13^{\mathbf{a}}$ & $190.75 \pm 4.50^{\mathbf{c}}$ & $206.00 \pm 2.80^{\mathbf{b}}$ & $193.75 \pm 2.87^{\mathbf{b c}}$ \\
Copper & $39.68 \pm 1.08^{\mathbf{c}}$ & $48.23 \pm 1.37^{\mathbf{a}}$ & $38.50 \pm 0.76^{\mathbf{c}}$ & $44.80 \pm 0.60^{\mathbf{b}}$ \\
Urea & $30.00 \pm 1.08^{\mathbf{b}}$ & $34.00 \pm 1.47^{\mathbf{b}}$ & $26.00 \pm 1.47^{\mathbf{b c}}$ & $22.75 \pm 2.02^{\mathbf{c}}$ \\
Creatinine & $0.60 \pm 0.04^{\mathbf{a}}$ & $0.68 \pm 0.06^{\mathbf{a}}$ & $0.61 \pm 0.06^{\mathbf{a b}}$ & $0.50 \pm 0.04^{\mathbf{b}}$ \\
Glucose & $94.05 \pm 3.04^{\mathbf{b}}$ & $120.17 \pm 2.08^{\mathbf{a}}$ & $83.06 \pm 4.27^{\mathbf{c}}$ & $92.20 \pm 2.43^{\mathbf{b}}$ \\
\hline
\end{tabular}

The means within the same row with different superscript letters are significantly differed at $(P<0.05)$ 
Table 4: Mean \pm SE of GST, CAT (U/g tissue) activities and GSH (umole/g tissue) levels in rabbit's liver, heart and kidney kept on high sucrose diet, olive leaves and oil

\begin{tabular}{ccccc}
\hline Control group & $\begin{array}{c}\text { High sucrose } \\
\text { group }\end{array}$ & $\begin{array}{c}\text { High sucrose + } \\
\text { Olive leaves } \\
\text { group }\end{array}$ & $\begin{array}{c}\text { High sucrose + } \\
\text { Olive oil group }\end{array}$ \\
\hline Liver & & & & \\
GST & $288.25 \pm 4.52^{\mathbf{a}}$ & $230.00 \pm 2.48^{\mathbf{b}}$ & $329.25 \pm 10.23^{\mathbf{a}}$ & $302.75 \pm 23.60^{\mathbf{a}}$ \\
CAT & $327.00 \pm 3.34^{\mathbf{a}}$ & $289.00 \pm 2.89^{\mathbf{c}}$ & $296.50 \pm 3.12^{\mathbf{b}}$ & $314.75 \pm 2.06^{\mathbf{a}}$ \\
GSH & $744.75 \pm 52.72^{\mathbf{a}}$ & $598.25 \pm 12.22^{\mathbf{b}}$ & $822.75 \pm 26.51^{\mathbf{a}}$ & $843.50 \pm 40.23^{\mathbf{a}}$ \\
Heart & & & & \\
GST & $149.50 \pm 4.37^{\mathbf{a}}$ & $121.25 \pm 4.27^{\mathbf{b}}$ & $150.50 \pm 3.80^{\mathbf{a}}$ & $131.00 \pm 4.10^{\mathbf{b}}$ \\
CAT & $80.00 \pm 3.19^{\mathbf{a}}$ & $60.75 \pm 1.65^{\mathbf{b}}$ & $70.25 \pm 0.85^{\mathbf{a}}$ & $72.00 \pm 4.81^{\mathbf{a}}$ \\
GSH & $36.25 \pm 1.31^{\mathbf{b}}$ & $29.75 \pm 0.85^{\mathbf{c}}$ & $46.50 \pm 1.32^{\mathbf{a}}$ & $43.00 \pm 1.47^{\mathbf{a}}$ \\
Kidneys & & & & \\
GST & $281.75 \pm 10.27^{\mathbf{a}}$ & $151.00 \pm 12.63^{\mathbf{c}}$ & $235.25 \pm 2.14^{\mathbf{b}}$ & $222.00 \pm 12.50^{\mathbf{b}}$ \\
CAT & $280.75 \pm 3.90^{\mathbf{a}}$ & $240.25 \pm 8.62^{\mathbf{c}}$ & $252.25 \pm 4.61 \mathrm{~b}^{\mathbf{c}}$ & $266.00 \pm 5.85^{\mathbf{a}}$ \\
GSH & $75.50 \pm 4.52^{\mathbf{a}}$ & $29.50 \pm 2.22^{\mathbf{c}}$ & $47.50 \pm 2.78^{\mathbf{b}}$ & $50.25 \pm 4.48^{\mathbf{b}}$ \\
\hline
\end{tabular}

The means within the same row with different superscript letters are significantly differed at $(\mathrm{P}<0.05)$

Table 5: Mean \pm SE of MDA (nmole/g tissue) and $\mathrm{H}_{2} \mathrm{O}_{2}(\mathrm{mM} / \mathrm{g}$ tissue) levels in rabbit's liver, heart and kidney kept on high sucrose diet, olive leaves and oil

\begin{tabular}{ccccc}
\hline Control group & $\begin{array}{c}\text { High sucrose } \\
\text { group }\end{array}$ & $\begin{array}{c}\text { High sucrose }+ \\
\text { Olive leaves } \\
\text { group }\end{array}$ & $\begin{array}{c}\text { High sucrose }+ \\
\text { Olive oil group }\end{array}$ \\
\hline Liver & & & & \\
MDA & $15.25 \pm 2.50^{\mathrm{c}}$ & $34.50 \pm 2.53^{\mathrm{a}}$ & $27.00 \pm 1.08^{\mathrm{ab}}$ & $25.50 \pm 3.38^{\mathrm{b}}$ \\
$\mathbf{H}_{2} \mathbf{O}_{2}$ & $13.25 \pm 0.80^{\mathrm{b}}$ & $45.73 \pm 1.05^{\mathrm{a}}$ & $12.30 \pm 2.41^{\mathrm{b}}$ & $13.53 \pm 0.65^{\mathrm{b}}$ \\
Heart & & & & \\
MDA & $691.75 \pm 20.38^{\mathrm{b}}$ & $795.00 \pm 6.96^{\mathrm{a}}$ & $595.25 \pm 14.64^{\mathrm{c}}$ & $557.50 \pm 8.54^{\mathrm{c}}$ \\
$\mathbf{H}_{2} \mathbf{O}_{2}$ & $0.78 \pm 0.06^{\mathrm{b}}$ & $1.05 \pm 0.06^{\mathrm{a}}$ & $0.83 \pm 0.05^{\mathrm{b}}$ & $0.80 \pm 0.06^{\mathrm{b}}$ \\
Kidneys & & & & \\
$\mathbf{M D A}$ & $29.00 \pm 3.08^{\mathrm{c}}$ & $85.50 \pm 2.47^{\mathrm{a}}$ & $30.00 \pm 2.04^{\mathrm{c}}$ & $39.50 \pm 2.10^{\mathrm{b}}$ \\
$\mathbf{H}_{2} \mathbf{O}_{2}$ & $0.74 \pm 0.11^{\mathrm{b}}$ & $5.20 \pm 0.40^{\mathrm{a}}$ & $0.41 \pm 0.07^{\mathrm{b}}$ & $0.73 \pm 0.04^{\mathrm{b}}$ \\
\hline
\end{tabular}

The means within the same row with different superscript letters are significantly differed at $(\mathrm{P}<0.05)$ 